\title{
Branching Patterns of the Facial Nerve within the Parotid Gland Among Sudanese
}

\author{
Mohammed Ahmed Idrees Saadelnour ${ }^{1,2 *}$ and Yasser Siddig Abdulghani ${ }^{3}$ \\ ${ }^{1}$ Otolaryngology Department (ENT), Sudan Medical Specialization Board, Khartoum, Sudan \\ ${ }^{2}$ Faculty of Medicine, University of Kordofan, El Obeid, Sudan \\ ${ }^{3}$ Faculty of Medicine, The National Ribt University, Khartoum, Sudan
}

*Corresponding author: Mohammed Ahmed Idrees Saadelnour, Department of Otolaryngology, Medical Specialization Board, Khartoum, Sudan

\section{ARTICLE INFO}

Received: 慧 July 23, 2021

Published: 㓞 August 03, 2021

Citation: Mohammed Ahmed Idrees Saadelnour, Yasser Siddig Abdulghani. Branching Patterns of the Facial Nerve within the Parotid Gland Among Sudanese. Biomed J Sci \& Tech Res 37(4)-2021. BJSTR. MS.ID.006042.

Keywords: Facial Never; Sudanese; Dissections; Parotid Region
ABSTRACT

Background: This study examines the anatomic relationships and variability of the facial nerve trunk and its branches, with emphasis on the intraparotid region. The study aims to identify the variations of the course and main divisions of the facial nerve in Sudanese people.

Methods: This is a descriptive, cross-sectional study, done in Khartoum and North Kordofan states, Sudan. Between April to June 2017. Dissections were performed on 21 Sudanese heads on one site, and the facial nerve trunks and branches were exposed.

Results: The bifurcation of the temporofacial (upper) and cervicofacial (lower) divisions was seen in all dissections (100\%), the division was pre parotid in (76.1\%), intraparotid in $(23.9 \%)$. No post parotid division has seen. The retromandibular vein was found to be medial to the nerve in $(76.1 \%)$, lateral to it in (19\%) and in one cadaver it was in between nerve divisions (4.7\%).

Conclusion: Familiarity with these common variations in the facial anatomy provides useful information for the surgeon in careful dissection, preservation of the facial nerve, and complete removal of the tumours in the parotid region.

\section{Introduction}

The extratemporal component of the facial nerve starts when the facial nerve exits the stylomastoid foramen [1,2]. In the adult, it is protected laterally by the mastoid tip, tympanic ring, and mandibular ramus, whereas in children younger than 2 years it is relatively superficial [3]. Postauricular incisions in this younger population must be carefully planned because the trunk of the facial nerve is a subcutaneous structure at this level $[1,4]$. After exiting the stylomastoid foramen, the facial nerve gives off motor branches to the posterior belly of digastric, stylohyoid, and the superior auricular, posterior auricular, and occipitalis muscles [5]. The facial nerve then travels along a course anterior to the posterior belly of the digastric and lateral to the external carotid artery and styloid process before dividing into its main motor branches at the posterior edge of the parotid gland. The facial nerve trunk is usually identified approximately $1 \mathrm{~cm}$ deep and just inferior and medial to the tragal pointer [6].

The parotid and superficial musculoaponeurotic system (SMAS) can then be carefully divided to expose the facial nerve for facial nerve reconstruction [7]. Alternatively, branches of the facial nerve can be identified distally as they exit the anterior border of the parotid gland. Here, the buccal branches of the facial nerve become quite superficial, lying immediately beneath the SMAS. Facial nerve branches are then traced posteriorly to the main facial nerve trunk. Advocates of this technique note that damage to a small branch of the facial nerve during the initial exploration is far less devastating than an inadvertent injury to the entire motor trunk. However, 
these peripheral branches are more difficult to identify because of their smaller size and a lack of consistent landmarks [8-10]. The barbarization of the extratemporal facial nerve typically begins within the substance of the parotid gland and ultimately gives rise to the cervical, marginal mandibular, buccal, zygomatic, and frontal (or temporal) nerve branches [11]. The aim of this study is to describe variations of the course and main divisions of the facial nerve in Sudanese people -cadaveric study.

\section{Materials and Methods}

\section{Study Design}

A descriptive, cross-sectional study.

\section{Study Area}

Dissection rooms of the Sudanese Medical colleges in Khartoum and North Kordofan states.

\section{Study Duration}

In the time between April to June 2017.

\section{Data Collection}

Data collection sheet.

\section{Sample Size and Sample Technique}

I shall collect 20 random samples of cadavers from about 7-10 medical schools.

\section{Data Analysis}

Data analysed by SPSS (Statistical Package for Social Sciences).

\section{Result}

Research about a pattern of branching of the Facial nerve within the parotid region was done after dissecting 10 cadavers fixed with formalin bilaterally and one cadaver unilaterally.

The following were observed:

- 16 facial nerves were divided before reaching the parotid gland. Show Table 1 and Figure 1.
- $\quad 5$ facial nerves were divided within the substance of the gland.

- $\quad$ No post parotid division was observed.

- In one cadaver on the right side the division was pre parotid while on the left side it was within the parotid gland substance.

\section{Relation of the Facial Nerve to Retromandibular Vein}

In 7 cadavers the retromandibular vein was medial to the facial nerve, In one cadaver the vein lies in between nerve divisions on the left side and medial to the nerve on the right side. In Two cadavers the retromandibular nerve was lateral to the facial nerve. show Tables 2-5 and Figures 2-4. In all the dissected cadavers the facial nerves were divided into upper and lower trunks only.

Table 1: Shows the site of division of the Facial nerve in relation to parotid gland.

\begin{tabular}{|c|c|c|}
\hline Preparotid & Within the parotid & Post parotid \\
\hline 16 & 5 & 0 \\
\hline
\end{tabular}

Table 2: Shows Relation the of the facial nerve to Retromandibular Vein.

\begin{tabular}{|c|c|c|}
\hline $\begin{array}{c}\text { Medial to the Facial } \\
\text { Nerve }\end{array}$ & $\begin{array}{c}\text { Lateral to the Facial } \\
\text { Nerve }\end{array}$ & $\begin{array}{c}\text { In between the facial } \\
\text { Nerve }\end{array}$ \\
\hline 16 & 4 & 1 \\
\hline
\end{tabular}

Table 3: Shows the No. of divisions.

\begin{tabular}{|c|c|c|}
\hline One division & Two divisions & Three divisions \\
\hline 0 & 21 & 0 \\
\hline
\end{tabular}

Table 4: Compare between Sudanese and Turkey study.

\begin{tabular}{|c|c|c|}
\hline Retromandibular Vein & $\begin{array}{c}\text { In Sudanese } \\
\text { study }\end{array}$ & In Turkey study \\
\hline Medial to the Facial Nerve & $76.19 \%$ & $90 \%$ \\
\hline Lateral to the Facial Nerve & $19.04 \%$ & $0 \%$ \\
\hline In between the facial Nerve & $4.76 \%$ & $10 \%$ \\
\hline
\end{tabular}

Table 5: Compare between Sudanese, Korean and Malaysian studies.

\begin{tabular}{|c|c|c|c|}
\hline $\begin{array}{c}\text { Trifurcation } \\
\text { Pattern }\end{array}$ & $\begin{array}{c}\text { In Sudanese } \\
\text { study }\end{array}$ & $\begin{array}{c}\text { In Korean } \\
\text { study }\end{array}$ & $\begin{array}{c}\text { In Malaysian } \\
\text { study }\end{array}$ \\
\hline Percentage & $0 \%$ & $13.30 \%$ & $3.80 \%$ \\
\hline
\end{tabular}




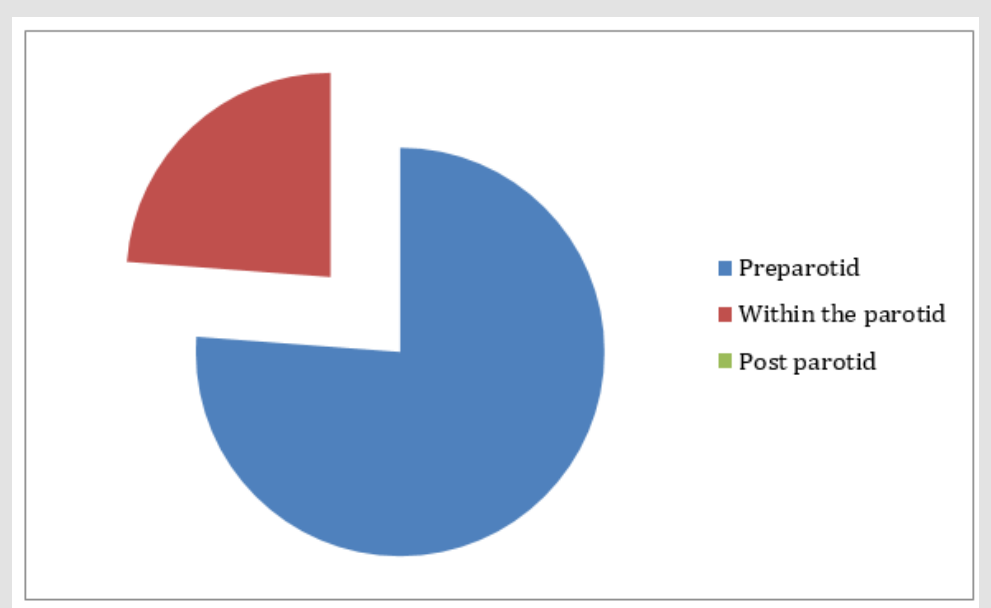

Figure 1: Shows the site of division of the Facial nerve in relation to parotid gland.

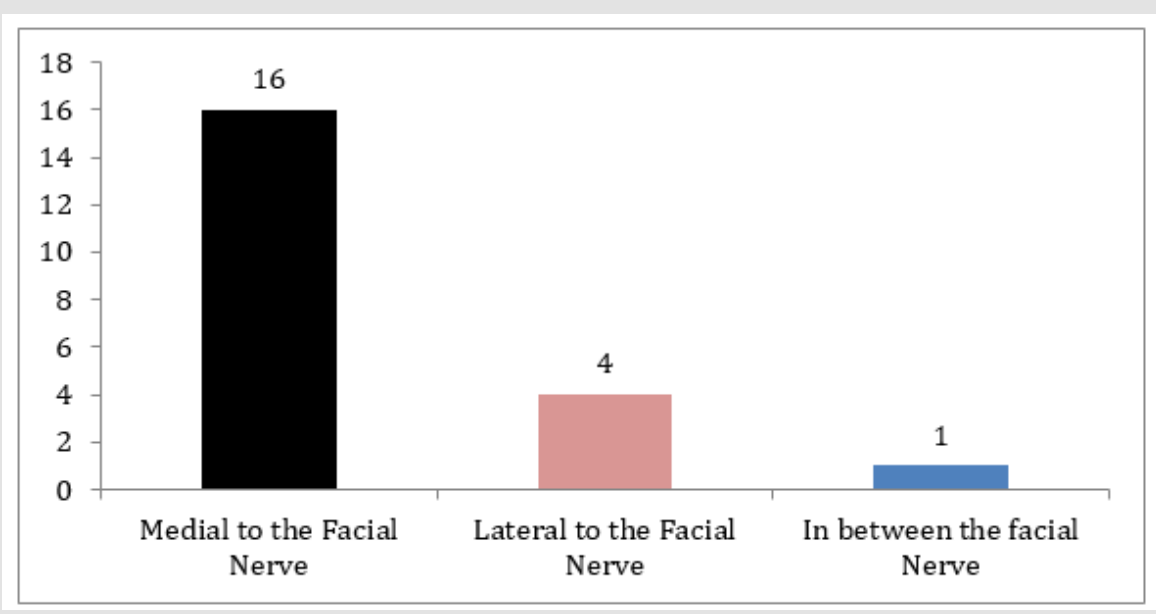

Figure 2: Relation of the facial nerve to Retromandibular Vein.

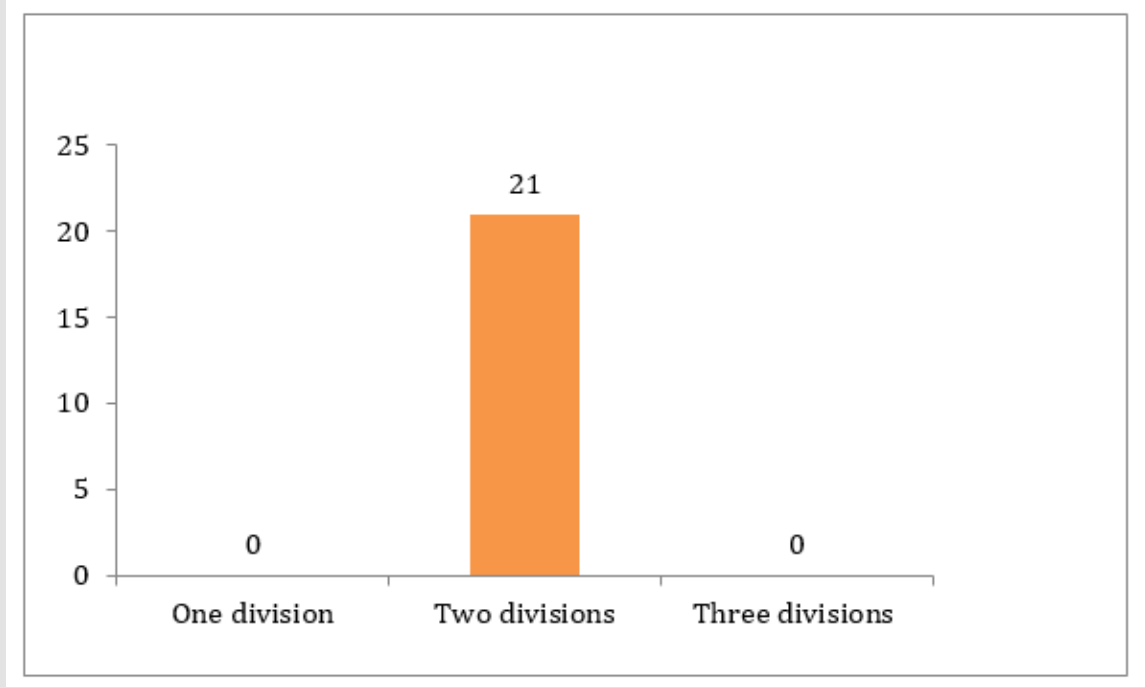

Figure 3: Shows the No. of divisions. 


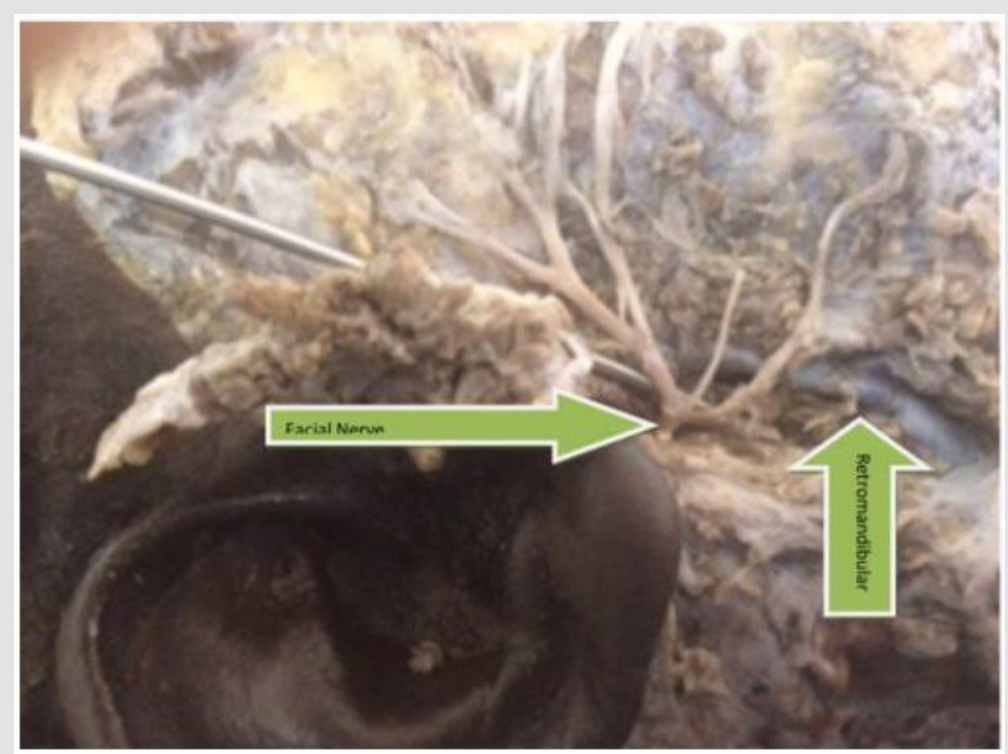

Figure 4: Show a dissected part of the facial nerve.

\section{Discussion}

Knowledge of the main landmark of the facial nerve trunk is crucial for safe and effective surgical outcome in the region of the parotid gland [12]. The branching pattern of the facial nerve within the parotid region shows individual variations [13-15]. This study examines the anatomic relationships and variability of the facial nerve trunk and its branches [16], with emphasis on the site of division in relation to the parotid gland, number of divisions and the position of the retromandibular vein in comparison to the facial nerve $[17,18]$. Dissections were performed on 11 Sudanese cadavers fixed with formalin; 21 half-heads has bees dissected [19], and the facial nerve trunks and branches were exposed [20]. The facial nerve trunk bifurcated into two main divisions in all cases $(100 \%)$, and no trifurcation pattern was seen (0\%). In 16 cases $(76.19 \%)$ it bifurcates before the parotid gland, while in 5 cases $(23.8 \%)$ it bifurcates within the gland. In one cadaver the bifurcation on the right side was before the parotid while on the left side it was within the gland [21,22].

We also investigated the relationship between the facial nerve and the retromandibular vein. In 16 (76.19\%) of the cases the retromandibular vein was located on the medial side of the upper and lower trunks of the facial nerve, and in 4 (19.04\%), the course of the retromandibular vein was lateral to the lower and upper trunks [23]. In one (4.76\%) case the retromandibular vein was medial to the upper trunk and lateral to the lower trunk, the course of the retromandibular vein was different on the right and left sides of the face in the same cadaver $[24,25]$. A study in Korean cadavers revealed that $(86.7 \%)$, the facial nerve trunk bifurcated into two main divisions, and a trifurcation pattern was seen in the other cases (13.3\%) [26]. Another study in Turkey 50 dissections were performed in 30 cadavers in $(90 \%)$ of the cases the retromandibular vein was located on the medial side of the upper and lower trunks of the facial nerve [27], and in (10\%) the course of the retromandibular vein was lateral to the lower trunk and medial to the upper trunk. also, there is a study done in 79 facial halves from formalin-fixed cadavers in Malaysian subjects .trifurcation was seen in three facial halves (3.8\%) [28-30]. For me the absence of trifurcation pattern in Sudanese people compared To those in Turkey and Malaysian could be due to racial and environmental differences [31,32].

\section{In Conclusion}

The facial nerve trunk bifurcated into two main divisions in all cases (100\%), in 16 cases it bifurcates before the parotid gland, 5 cases it bifurcates within the gland and only one cadaver the bifurcation on the right side was before the parotid while on the left side it was within the gland. In 16 of the cases the retromandibular vein was located on the medial side of the upper and lower trunks of the facial nerve, four of them course of the retromandibular vein was lateral to the lower and upper trunks, In one case the retromandibular vein was medial to the upper trunk and lateral to the lower trunk.

\section{Ethical Clearance}

Permission and ethical clearance was obtained from anatomy head departments in target medical schools.

\section{Conflict of Interest}

None. 


\section{Written Consent from the Patient}

Obtained.

\section{Funding}

No fund have been received

\section{Availability of Data and Materials}

All the data used in the study are available from the first and corresponding author on reasonable request.

\section{References}

1. O'Rahilly R (1988) On counting cranial nerves. Acta Anat (Basel) 133(1) 3-4.

2. Steinberg DA (2002) Scientific neurology and the history of the clinical examination of selected motor cranial nerves. Semin Neurol 22(4): 349356.

3. Bell C (1821) On the nerves, giving an account of some experiments on their structure and functions, which leads to a new arrangement of the system. Trans R Soc Lond 3: 398.

4. Bell C (1830) The Nervous System of the Human Body ( $2^{\text {nd }}$ Edn.). London: Longman's.

5. Crosby EC, Dejonge BR (1963) Experimental and clinical studies of the central connections and central relations of the facial nerve. Ann Otol Rhinol Laryngol 72: 735-755.

6. Lang J (1985) Anatomy of the brainstem and the lower cranial nerves, vessels, and surrounding structures. Am J Otol, p. 1-19.

7. May M (1973) Anatomy of the facial nerve (spatial orientation of fibers in the temporal bone). Laryngoscope 83(8): 1311-1329.

8. May M (2000) Anatomy for the clinician. In: May M, Schaitkin BM (Eds.), The FacialNerve. ( $2^{\text {nd }}$ Edn.)., New York: Thieme, p. 19-56.

9. Podvinec M, Pfaltz CR (1976) Studies on the anatomy of the facial nerve. Acta Otolaryngol (Stockh) 81(3-4): 173-177.

10. Harris WD (1968) Topography of the facial nerve. Arch Otolaryngol 88(3): 264-267.

11. Kukwa A, Czarnecka E, Oudghiri J (1984) Topography of the facial nerve in the stylomastoid fossa. Folia Morphol (Warsz) 43(4): 311-314.

12. Sunderland S (1953) The structure of the facial nerve. Anat Rec 116 147-165.

13. Wysocki J (1998) Correlations between topography of the main structures of the temporal bone and the location of the sigmoid sinus [in Polish]. Otolaryngol Pol 52: 287-290.

14. Fisch U, Esslen E (1972) Total intratemporal exposure of the facial nerve. Pathologic findings in Bell's palsy. Arch Otolaryngol 95(4): 335-341.

15. Nakashima S, Sando I, Takahashi H, Fujita S (1993) Computeraided 3-D reconstruction and measurement of the facial canal and facial nerve. I. Cross-sectional area and diameter: preliminary report. Laryngoscope 103(10):1150-1156.
16. Hunt JR (1907) On herpetic inflammation of the geniculate ganglion. A new syndrome and its complications. J New Ment Dis 34: 73-96.

17. Rouviere H, Delmas A (1985) Nerfs de la tet et du cou. In: eds. Anatomie Humaine: Descriptive Topographique et Functionnelle. Paris: Masson 276

18. Hitselberger WE, House WF (1966) Acoustic neuroma diagnosis: External auditory canal hypesthesia as an early sign. Arch Otolaryngol 83(3): 218-221.

19. Wilhelmi BJ, Mowlavi A, Neumeister MW (2003) The safe face lift with bony anatomic landmarks to elevate the SMAS. Plast Reconstr Surg 111(5): 1723-1726.

20. Davis RA, Anson BJ, Puddinger JM, Kurth RE (1956) Surgical anatomy of the facial nerve and parotid gland based upon study of 350 cervical facial halves. Surg Gynecol Obstet 102(4): 385-412.

21. Baker DC, Conley J (1979) Avoiding facial nerve injuries in rhytidectomy. Anatomical variations and pitfalls. Plast Reconstr Surg 64(6): 781-795.

22. Pitanguy I, Ramos AS (1966) The frontal branch of the facial nerve: the importance of its variations in face lifting. Plast Reconstr Surg 38(4): 352-356.

23. Stuzin JM, Wagstrom L, Kawamoto HK, Wolfe SA (1989) Anatomy of the frontal branch of the facial nerve: the significance of the temporal fat pad. Plast Reconstr Surg 83(2): 265-271.

24. Gosain AK, Sewall SR, Yousif NJ (1997) The temporal branch of the facial nerve: how reliably can we predict its path? Plast Reconstr Surg 99(5):1224-1233

25. Sabini P, Wayne I, Quatela VC (2003) Anatomical guides to precisely localize the frontal branch of the facial nerve. Arch Facial Plast Surg 5(2): 150-152.

26. Dingman RO, Grabb WC (1962) Surgical anatomy of the mandibular ramus of the facial nerve based on the dissection of 100 facial halves. Plast Reconstr Surg 29: 266-272.

27. Seckel BR(1993) Facial Danger Zones: Avoiding Nerve Injury in Facial Plastic Surgery. Saint Louis: Quality Medical Publishers.

28. Freilinger G, Gruber H, Happak W, Pechmann U(1987) Surgical anatomy of the mimic muscle system and the facial nerve: importance for reconstructive and aesthetic surgery. Plast Reconstr Surg 80(5):686690.

29. Happak W, Burggasser G, Liu J, Gruber H, Freilinger G (1994) Anatomy and histology of the mimicmuscles and the supplying facial nerve. Eur Arch Otorhinolaryngol, p. S85-S86.

30. Freilinger G, Happak W, Burggasser G, Gruber H (1990) Histochemical mapping and fiber size analysis of mimic muscles. Plast Reconstr Surg 86(3): $422-428$

31. Happak W, Liu J, Burggasser G, Flowers A, Gruber H, et al. (1997)Human facial muscles: dimensions, motor endplate distribution, and presence of muscle fibers with multiple motor endplates. Anat Rec 249(2): 276284.

32. Bischoff EPE (1977) Microscopic analysis of the anastomosis between the cranial nerves. In: Sacks EJ, Valtin EW (Eds.)., Hanover, NH: University Press of New England. 
ISSN: 2574-1241

DOI: 10.26717/BJSTR.2021.37.006042

Mohammed Ahmed Idrees Saadelnour. Biomed J Sci \& Tech Res

(c) (P) This work is licensed under Creative BY Commons Attribution 4.0 License

Submission Link: https://biomedres.us/submit-manuscript.php

\begin{tabular}{ll} 
BIOMEDICAL & Assets of Publishing with us \\
RESEARCHES & - Global archiving of articles \\
& - Immediate, unrestricted online access \\
\hline - Rigorous Peer Review Process
\end{tabular}

